\title{
Clinical Characteristics of Haemophilus influenzae at General Hospital in the Central Region of Japan
}

\author{
Masaaki Minami1 ${ }^{*}$, Ryoko Sakakibara², Taichi Imura², Mika Watanabe ${ }^{2}$, Hideo Morita², \\ Naoto Kanemaki ${ }^{3}$, Michio Ohta ${ }^{4}$ \\ ${ }^{1}$ Department of Bacteriology, Graduate School of Medical Sciences, Nagoya City University, Nagoya, Japan \\ ${ }^{2}$ Department of Clinical Investigation, Daido Hospital, Nagoya, Japan \\ ${ }^{3}$ Department of Gastroenterology, Daido Hospital, Nagoya, Japan \\ ${ }^{4}$ School of Nursing, Sugiyama Jyogakuen University, Nagoya, Japan \\ Email: "minami@med.nagoya-cu.ac.jp
}

Received 14 April 2016; accepted 19 May 2016; published 24 May 2016

\begin{abstract}
Haemophilus influenzae is an important pathogen that caused several infection diseases, such as sinusitis, otitis media, sepsis, and meningitis. This study was conducted to find out the prevalence and antimicrobial susceptibility pattern of Haemophilus influenzae isolates at general hospital in the central region of Japan from December 2015 to January 2016. Haemophilus influenzae was identified by standard laboratory procedure. Antimicrobial susceptibility testing was performed by micro dilution assay according to CLSI recommendation. One hundred ninety-one Haemophilus influenzae were isolated, among which $95(49.7 \%)$ were from male and $96(50.3 \%)$ were from female. The age incidence of $(0)$ years, $(\leq 2)$ years, $(\leq 5)$ years, and $(6 \leq)$ years groups were $22(11.5 \%)$, 92(48.2\%), 61(31.9\%), and 16(8.4\%), respectively. Positive samples were received mostly from the nasal discharge $(177 / 92.7 \%)$, sputum $(6 / 3.1 \%)$, tonsillar $(6 / 3.1 \%)$, and pharynx $(2 / 1.0 \%)$. Ceftriaxone was the most active antibiotics with $100 \%$ susceptible rates, followed by ciprofloxacin $(\mathbf{9 9 . 5 \% )}$ and minocycline $(\mathbf{9 9 \%})$ in our study. Furthermore, we categorized four patterns: beta lactamase-negative ampicillin-sensitive strain (BLNAS), beta lactamase-negative ampicillin-resistant strain (BLNAR), beta lactamase-positive ampicillin resistant strain (BLPAR), and beta lactamase-positive amoxicillin-clavulanic acid-resistant strain (BLPACR) from those ampicillin susceptible results. The numbers of female were significant greater than those of male in BLPAR $(p=$ 0.0336). With respect to antimicrobial susceptible pattern, there was no minocycline and piperacillin resistant strain in both BLNAS and BLNAR $(p<0.0001)$. Haemophilus influenzae infection spreads worldwide and inadequate use of antibiotics contributes to uptake of their new antimicrobial resistance. Continuous antimicrobial surveys are need for control the emergence and spread of antimicrobial resistance to reduce the morbidity and mortality.
\end{abstract}

\section{Keywords}

Haemophilus influenzae, Susceptibility, Antimicrobial Resistance

\footnotetext{
${ }^{*}$ Corresponding author.
}

How to cite this paper: Minami, M., Sakakibara, R., Imura, T., Watanabe, M., Morita, H., Kanemaki, N. and Ohta, M. (2016) Clinical Characteristics of Haemophilus influenzae at General Hospital in theCentral Region of Japan. Journal of Biosciences and Medicines, 4, 18-23. http://dx.doi.org/10.4236/jbm.2016.46003 


\section{Introduction}

Haemophilus influenzae is a Gram-negative bacterium which is isolated from the upper respiratory tract of certain normal humans. It is a major cause of bacterial meningitis in children aged under 5 years old and is also a significant agent of respiratory tract infections, including acute otitis media, sinusitis, pneumonia, and other serious invasive infections [1]. In elderly individuals, particularly those with underlying lung disease, Haemophilus influenzae can cause severe pneumonia. Of all six serotypes (a - f) of Haemophilus influenzae, serotype b caused the most invasive diseases prior to the introduction of the Haemophilus influenzae type b (Hib) vaccine [2] [3]. When the conjugate vaccine was introduced, the incidence of invasive Hib disease has been reduced significantly [4]. However, Hib immunization has yet to be included in routine childhood vaccinations in many countries, and Haemophilus influenzae remains one of the most important causes of community-acquired pneumonia [5]. In the past, ampicillin had been recommended as the drug of first choice for Haemophilus influenzae infection. However, the first ampicillin-resistant Haemophilus influenzae was reported in 1974 in several countries [6]. The major mechanism of this resistance was the production of beta-lactamases [7]. Non-beta-lactamase-mediated resistance to ampicillin in Haemophilus influenzae was first reported in the early 1980s [8]. This beta-lactamase-negative ampicillin-resistant (BLNAR) determinant was associated with the alteration of penicillin-binding proteins (PBPs) as a result of ftsI gene mutation [9] [10]. Prevalence of BLNAR among Haemophilus influenzae has been increasing in various countries in Europe and Asia [11] [12].

The present study was conducted to find out the recent clinical characteristics of Haemophilus influenzae isolates at general hospital in the central of Japan.

\section{Materials and Methods}

\subsection{Strains and Clinical Data Collection}

A total of 191 Haemophilus influenzae was obtained from various clinical specimens at Daido Hospital from December 2015 to January 2016. Daido Hospital is a 404-bed private general hospital in the central region of Japan. We used medical records appended to clinical species for the analysis of clinical feature at Daido Hospital. We considered several isolates from the same region of the same patient as one isolate per one patient for the analysis in this study. All Haemophilus influenzae isolates were identified by standard conventional biochemical methods or the VITEK2 system (bioMérieux, Durham, NC, USA). Our experimental design was approved by the ethics committee at Daido hospital.

\subsection{Antimicrobial Susceptibility Analysis}

Haemophilus influenzae isolates were examined for seven antimicrobial susceptibilities as follows; Ampicillin (ABPC), sulbactum/Ampicillin (SBT/ABPC), Clarithromycin (CAM), Ceftriaxone (CTX), Ciprofloxacin (CPFX), Minocycline (MINO), and Piperacillin (PIPC). Minimal inhibitory concentrations (MICs) were determined at clinical laboratory in Daido Hospital using broth micro dilution methodology with the VITEK2 system. Evaluation of susceptibilities was calculated based on Clinical Laboratory Standard Institute (CLSI) break point [13]. We defined the ampicillin-resistant Haemophilus influenzae as follows; beta lactamase-negative ampicillin-sensitive strain (BLNAS): the MIC of ABPC $\leq 1$, beta lactamase-negative ampicillin-resistant strain (BLNAR): the MIC of $\mathrm{ABPC}=2$, beta lactamase-positive ampicillin resistant strain (BLPAR): the MIC of $\mathrm{ABPC} \geq 4$ and the $\mathrm{MIC}$ of $\mathrm{SBT} / \mathrm{ABPC} \leq 1$, beta lactamase-positive amoxicillin-clavulanic acid-resistant strain (BLPACR): the MIC of $\mathrm{ABPC} \geq 4$ and the MIC of SBT/ABPC $\geq 2$ [14].

\subsection{Statistical Analysis of the Data}

We conducted the statistical analysis with the chi-squared test or Fisher's exact test when appropriate. Differences were considered significant when $p$ was $<0.05$.

\section{Results}

First of all, we screened the ampicillin susceptibility of all Haemophilus influenzae isolates. From those ampicillin susceptible results, we categorized four patterns: BLNAS, BLNAR, BLPAR, and BLPACR (Table 1). 
Table 1. Clinical characteristic of Haemophilus influenzae isolates.

\begin{tabular}{|c|c|c|c|c|c|c|}
\hline \multirow{2}{*}{ Characteristics and description } & \multirow{2}{*}{ Total number of isolates } & \multicolumn{4}{|c|}{ Number of isolates } & \multirow{2}{*}{$p$ value } \\
\hline & & BLNAS & BLNAR & BLPAR & BLPACR & \\
\hline \multicolumn{7}{|l|}{ Gender } \\
\hline Male & 95 & 26 & 22 & 3 & 44 & \multirow{2}{*}{0.0336} \\
\hline Female & 96 & 36 & 16 & 11 & 33 & \\
\hline \multicolumn{7}{|l|}{ Age } \\
\hline 0 & 22 & 4 & 4 & 2 & 12 & 0.3990 \\
\hline$\leq 2$ & 92 & 28 & 19 & 9 & 36 & 0.6162 \\
\hline$\leq 5$ & 61 & 21 & 13 & 3 & 24 & 0.9203 \\
\hline $6 \leq$ & 16 & 9 & 2 & 0 & 5 & 0.1604 \\
\hline \multicolumn{7}{|l|}{ Speciemen type } \\
\hline Nasal discharge & 177 & 54 & 37 & 14 & 72 & 0.1539 \\
\hline Sputum & 6 & 4 & 1 & 0 & 1 & 0.3107 \\
\hline Tonsillar & 6 & 2 & 0 & 0 & 4 & 0.4310 \\
\hline Pharynx & 2 & 2 & 0 & 0 & 0 & 0.2401 \\
\hline Total & 191 & 62 & 38 & 14 & 77 & \\
\hline
\end{tabular}

Next, we compared the differences of clinical characteristics and antimicrobial susceptible pattern except ampicillin among ampicillin-resistant Haemophilus influenzae in this study. One hundred ninety-one Haemophilus influenzae were isolated among which 95(55.6\%) were from male and 96(44.4\%) were from female (Table 1). According to ampicillin susceptibility, the numbers of female were significant greater than those of male in $\operatorname{BLPAR}(p=0.0336)$. The age incidence among 0 years age group was $22(11.5 \%), \leq 2$ years age group, 92(48.2\%), $\leq 5$ years age group, 61(31.9\%), and $6 \leq$ years it was 16(8.4\%) (Table 1). According to ampicillin susceptibility, there was no significant difference in age group. Most of the Haemophilus influenzae isolates were from nasal discharge (177/92.7\%), followed by sputum (6/3.1\%), tonsillar (6/3.1\%) and pharynx (2/1.0\%) (Table 1). According to ampicillin susceptibility, there was no significant difference in specimen group.

The results of antimicrobial susceptible patterns of Haemophilus influenzae isolates to various antibiotics tested in this study were shown in Table 2. Ceftriaxone was the most active antibiotics with $100 \%$ susceptible rates, followed by ciprofloxacin (99.5\%) and minocycline (99\%). According to ampicillin susceptibility, there was no minocycline and piperacillin resistant strain in both BLNAS and BLNAR.

\section{Discussion}

In this study, we described the characteristics of Haemophilus influenzae isolates from July 2014 to June 2015 at general hospital in the central region of Japan. With respect to gender group, our study showed the male to female ratio was about 0.99 and there were no significant differences among gender. We clarified Haemophilus influenzae with age distribution. The present study reveals the about half of Haemophilus influenzae were isolated from under 2 years age patients. In the analysis of specimen's type, we found that specimens where most patients with Haemophilus influenzae were detected were nasal discharge. In the analysis of antimicrobial susceptibility, we did not find any ceftriaxone-resistant Haemophilus influenzae in our study. Furthermore, in our study, ciprofloxacin, minocycline, and piperacillin were also effective antibacterial agent against Haemophilus influenzae, especially BLNAS and BLNAR. However, about 23\% of Hemophilus influenzae were non-susceptible to clarithromycin. As ampicillin-resistant Haemophilus influenzae spreads widely, several investigators reported antimicrobial susceptible patterns of Haemophilus influenzae in Asian country. 
Table 2. Antimicrobial non-susceptible patterns of Haemophilus influenzae isolates.

\begin{tabular}{|c|c|c|c|c|c|}
\hline \multirow{2}{*}{ Antimicrobial agent non-susceptibility } & \multicolumn{4}{|c|}{ Number of isolates } & \multirow{2}{*}{$p$ value } \\
\hline & BLNAS & BLNAR & BLPAR & BLPACR & \\
\hline Clarithromycin intermediate & 12 & 5 & 1 & 10 & 0.5796 \\
\hline Clarithromycin resistant & 3 & 4 & 1 & 8 & 0.6427 \\
\hline Ceftriaxione resistant & 0 & 0 & 0 & 0 & N.D. \\
\hline Ciprofloxacin resistant & 1 & 0 & 0 & 0 & 0.5536 \\
\hline Minocycline resistant & 0 & 0 & 1 & 1 & 0.1056 \\
\hline Piperacillin resistant & 0 & 0 & 12 & 9 & $<0.0001$ \\
\hline
\end{tabular}

In Japan, the prevalence of BLNAR was $63.5 \%$ and the rate of BLPAR also ranged from $6.4 \%$ to $8.7 \%$ from acute otitis media patient [15]. Another Japanese report from acute otitis media patients showed that the rate of BLNAR and BLPAR were $60.5 \%$ and $8.3 \%$ [16]. Furthermore, the prevalence of BLNAR, BLPAR, and BLPACR were 62.4, 6.1, and 4.1\% in other Japanese study [17]. The rate of levofloxacin-resistant was $24.3 \%$ in another Japanese report [18]. In South Korea, the rate of BLNAR, BLPAR, and BLPACR were 40.2, 9, and 24.6 [19].

In China, the rate of beta-lactamase positive was 35.8\% [20]. In another Chinese report, the rate of beta-lactamase positive was $61 \%$ and the rate of tetracycline resistant was $94.5 \%$ [21]. In Thailand, the rate of ampicillin resistant, tetracycline resistant, clarithromycin resistant, and ciprofloxacin resistant bacteria were 50, 31.9, 5.7, and $0 \%$, respectively [22]. In Turkey, the rate of ampicillin/clavulanic acid resistant, tetracycline resistant, clarithromycin resistant, and ciprofloxacin resistant bacteria were $0,15,4$, and $0 \%$, respectively [23]. In our case, the prevalence of BLNAR, BLPAR, and BLPACR were 19.9, 7.3, and 40.3\% and the rate of beta-lactamase positive was $47.6 \%$. Our results are similar to the result in South Korea, not in Japan. For the other antibioticresistance except ampicillin, our result showed that the CPFX-, MINO, and CAM-resistant were 0.5, 1, and 8.4\%. The antibiotic resistant rates in our studies were relatively low compared to other country. Although Haemophilus influenzae spreads widely, the susceptibility patterns of Haemophilus influenzae in Asia have diversified by region [24]. Further analysis is needed for the clarification of epidemiology of Haemophilus influenzae in Asian countries.

\section{Conclusion}

Incidence of Haemophilus influenzae infection is increasing worldwide and may lead to severe invasive infection. Our investigation aims to guide medical staffs on appropriate use of antibiotics. Furthermore, our aim is not only to reduce the morbidity and mortality in the patients but also to control the emergence and spread of antimicrobial resistance among Haemophilus influenzae. Our results strongly emphasize the need for continuous epidemiological monitoring of antibiotic resistant Haemophilus influenzae.

\section{Acknowledgements}

We thank Mr. Masashi Ishihara and Ms. Miwako Fujimura for special encouragement. This study was supported by a grant-in-aid for research from the Nagoya City University, Japan.

\section{References}

[1] Ladhani, S., Slack, M.P., Heath, P.T., von Gottberg, A., Chandra, M., Ramsay, M.E., and European Union Invasive Bacterial Infection Surveillance Participants (2010) Invasive Haemophilus influenzae Disease, Europe, 1996-2006. Emerg. Infect. Dis., 16, 455-463. http://dx.doi.org/10.3201/eid1603.090290

[2] Watt, J.P., Wolfson, L.J., O’Brien, K.L., Henkle, E., Deloria-Knoll, M., McCall, N., et al. (2009) Burden of Disease Caused by Haemophilus influenzae Type b in Children Younger than 5 Years: Global Estimates. Lancet, 374, 903-911. http://dx.doi.org/10.1016/S0140-6736(09)61203-4

[3] Peltola, H. (1999) Spectrum and Burden of Severe Haemophilus influenzae Type b Diseases in Asia. Bull. World 
Health Organ., 77, 878-887.

[4] Peltola, H. (1998) Haemophilus influenzae Type b Disease and Vaccination in Europe: Lessons Learned. Pediatr. Infect. Dis. J., 17, S126-S132. http://dx.doi.org/10.1097/00006454-199809001-00007

[5] Apisarnthanarak, A. and Mundy, L.M. (2005) Etiology of Community-Acquired Pneumonia. Clin. Chest. Med., 26, 47-55. http://dx.doi.org/10.1016/j.ccm.2004.10.016

[6] Thornsberry, C. and Kieven, L.A. (1974) Antimicrobial Susceptibility of Haemohpilus influenzae. Antimicrob. Agents Chemother., 6, 620-624. http://dx.doi.org/10.1128/AAC.6.5.620

[7] Medeiros, A.A. and O’Brien, T.F. (1975) Ampicillin-Resistant Haemophilus influenzae Type b Possessing a TEM-Type Beta-Lactamase but Little Permeability Barrier to Ampicillin. Lancet, 1, 716-719. http://dx.doi.org/10.1016/S0140-6736(75)91630-X

[8] Markowitz, S.M. (1980) Isolation of an Ampicillin-Resistant, Non-Beta-Lactamase-Producing Strain of Haemophilus influenzae. Antimicrob. Agents. Chemother., 17, 80-83. http://dx.doi.org/10.1128/AAC.17.1.80

[9] Parr Jr., T.R., and Bryan, L.E. (1984) Mechanism of Resistance of an Ampicillin-Resistant, Beta-Lactamase-Negative Clinical Isolate of Haemophilus influenzae Type b to Beta-Lactam Antibiotics. Antimicrob. Agents. Chemother., 25, 747-753. http://dx.doi.org/10.1128/AAC.25.6.747

[10] Ubukata, K., Shibasaki, Y., Yamamoto, K., Chiba, N., Hasegawa, K., Takeuchi, Y., et al. (2001) Association of Amino Acid Substitutions in Penicillin-Binding Protein 3 with Beta-Lactam Resistance in Beta-Lactamase-Negative Ampicillin Resistant Haemophilus influenzae. Antimicrob. Agents. Chemother., 45, 1693-1699. http://dx.doi.org/10.1128/AAC.45.6.1693-1699.2001

[11] Fluit, A.C., Florijn, A., Verhoef, J., and Milatovic, D. (2005) Susceptibility of European Beta-Lactamase-Positive and -Negative Haemophilus influenzae Isolates from the Periods 1997/1998 and 2002/2003. J. Antimicrob. Chemother., 56, 133-138. http://dx.doi.org/10.1093/jac/dki167

[12] Hasegawa, K., Yamamoto, K., Chiba, N., Kobayashi, R., Nagai, K., Jacobs, M.R., et al. (2003) Diversity of Ampicillin-Resistance Genes in Haemophilus influenzae in Japan and the United States. Microb. Drug Resist., 9, 39-46. http://dx.doi.org/10.1089/107662903764736337

[13] Clinical and Laboratory Standards Institute (CLSI) (2014) Performance Standards for Antimicrobial Susceptibility Testing: 24th Informational Supplement. Clinical and Laboratory Standards Institute M100-S24, Wayne.

[14] Tristram, S., Jacobs, M.R. and Appelbaum, P.C. (2007) Antimicrobial Resistance in Haemophilus influenzae. Clin Microbiol Rev, 20, 368-389. http://dx.doi.org/10.1128/CMR.00040-06

[15] Shiro, H., Sato, Y., Toyonaga, Y., Hanaki, H. and Sunakawa, K. (2015) Nationwide Survey of the Development of Drug Resistance in the Pediatric Field in 2000-2001, 2004, 2007, 2010, and 2012: Evaluation of the Changes in Drug Sensitivity of Haemophilus influenzae and Patients’ Background Factors. J. Infect. Chemother, 21, 247-256. http://dx.doi.org/10.1016/j.jiac.2014.11.012

[16] Kakuta, R., Yano, H., Hidaka, H., Kanamori, H., Endo, S., Ichimura, S., et al. (2016) Molecular Epidemiology of Ampicillin-Resistant Haemophilus influenzae Causing acute Otitis Media in Japanese Infants and Young Children. Pediatr. Infect. Dis. J. http://dx.doi.org/10.1097/inf.0000000000001066

[17] Takakura, M., Fukuda, Y., Nomura, N., Mitsuyama, J., Yamaoka, K., Asano, Y., et al. (2012) Antibacterial Susceptibility Surveillance of Haemophilus influenzae Isolated from Pediatric Patients in Gifu and Aichi Prefectures (2009-2010). Jpn. J. Antibiot, 65, 305-321.

[18] Kuo, S.C., Chen, P.C., Shiau, Y.R., Wang, H.Y., Lai, J.F., Huang, W., et al. (2014) Levofloxacin-Resistant Haemophilus influenzae, Taiwan, 2004-2010. Emerg. Infect. Dis, 20, 1386-1390. http://dx.doi.org/10.3201/eid2008.140341

[19] Park, C., Kim, K.H., Shin, N.Y., Byun, J.H., Kwon, E.Y., Lee, J.W., et al. (2013) Genetic Diversity of the ftsI Gene in $\beta$-Lactamase-Nonproducing Ampicillin-Resistant and $\beta$-Lactamase-Producing Amoxicillin-/Clavulanic Acid-Resistant Nasopharyngeal Haemophilus influenzae Strains Isolated from Children in South Korea. Microb Drug Resist, 19, 224-230. http://dx.doi.org/10.1089/mdr.2012.0116

[20] Luo, C., Xia, Y., Liu, Q., Chu, L., Fu, X., Jing, C., et al. (2012) Antibiotic Resistance and Molecular Epidemiology of the Beta-Lactamase-Producing Haemophilus influenzae Isolated in Chongqing, China. APMIS, 120, 926-934. http://dx.doi.org/10.1111/j.1600-0463.2012.02921.x

[21] Zhu, H., Wang, A., Tong, J., Yuan, L., Gao, W., Shi, W., et al. (2015) Nasopharyngeal Carriage and Antimicrobial Susceptibility of Haemophilus influenzae among Children Younger than 5 Years of Age in Beijing, China. BMC Microbiol, 15, 6. http://dx.doi.org/10.1186/s12866-015-0350-7

[22] Lulitanond, A., Chanawong, A., Pienthaweechai, K., Sribenjalux, P., Tavichakorntrakool, R., Wilailuckana, C., et al. (2012) Prevalence of $\beta$-Lactamase-Negative Ampicillin-Resistant Haemophilus influenzae Isolated from Patients of a Teaching Hospital in Thailand. Jpn. J. Infect. Dis, 65, 122-125. 
[23] Kuvat, N., Nazik, H., Berkiten, R. and Öngen, B. (2015) TEM-1 and ROB-1 Presence and Antimicrobial Resistance in Haemophilus influenzae Strains, Istanbul, Turkey. Southeast Asian J. Trop. Med. Pub. Health, 46, 254-261.

[24] Peto, L., Nadjm, B., Horby, P., Ngan, T.T. and van Doorn, R. (2014) The Bacterial Aetiology of Adult CommunityAcquired Pneumonia in Asia: A Systematic Review. Trans. R. Soc. Trop. Med. Hyg, 108, 326-337.

http://dx.doi.org/10.1093/trstmh/tru058 